\title{
Gênero, IFA e design de cursos: relato de uma experiência
}

\author{
Genre, EAP and course design: \\ reporting an experience
}

\author{
Rosinda de Castro Guerra Ramos \\ (Universidade Federal de São Paulo)
}

\section{RESUMO}

Este artigo relata uma experiência vivenciada com/pelo grupo de pesquisa GEALIN, de trazer para a prática pedagógica a utilização de gêneros textuais. Iniciando pela contextualização do curso, apresentamse princípios que nortearam o design de um curso de leitura em Inglês para Fins Acadêmicos (IFA), baseado em gêneros textuais. Segue, então, seleção, decisões quanto a sequenciamento e às bases que guiaram a produção do material didático. Comentam-se problemas e soluções encontrados nessa tarefa, decorrentes de avaliações e da utilização do material em sala de aula. Ao final, são feitas considerações sobre esse uso para o desenvolvimento de cursos voltados para o ensino-aprendizagem de Linguas para Fins Acadêmicos.

Palavras-chave: Inglês para Fins Acadêmicos; IFA; Gêneros textuais; Design de cursos. 


\section{ABSTRACT}

This article reports GEALIN research group experience of bringing into pedagogical practice the use of textual genres. It begins by contextualizing the course and presenting the principles that guided the design of a genrebased reading course for English for Academic Purposes (EAP). Next, the selection and decisions related to course sequencing and the bases that guided the production of materials are presented. Comments on problems and solutions found in this task, due to evaluations and the use of the materials in the classroom, are made. Finally, Comments are made on such use to the development of Language for Specific courses.

Key-words: English for Academic Purpose; EAP; Textual genres; Course design.

\section{Introdução}

Nas últimas décadas a Linguística Aplicada assistiu a um crescente e rápido desenvolvimento de pesquisas na área de estudos sobre gêneros textuais. Um grande interesse por parte de pesquisadores (Miller 1984; Martin 1984, 2000; Swales 1981, 1986, 1990, 2004; Bhatia 1993, 2004; Bazerman 2005, 2006; Marchuschi 2008) tem produzido não só grande conhecimento teórico nessa área, mas também esforços para se criar uma pedagogia baseada em gêneros.

No Brasil, aplicações sobre o ensino baseado em gêneros (cf.: Dionísio; Machado; Bezerra 2002; Meurer e Motta-Roth 2002; Rojo 2005) começaram a chamar a atenção de designers de materiais e professores no contexto de ensino-aprendizagem de língua materna, intensificado mais fortemente com a publicação dos Parâmetros Curriculares Nacionais (Brasil 1998, 1999). Já na área de línguas estrangeiras e principalmente na de Inglês para Fins Específicos (também conhecida como Instrumental ou ESP), na qual internacionalmente pesquisas sobre a utilização de gêneros já são publicadas desde meados dos anos 1980 (Dudley- Evans 1987; Swales 1990, por exemplo) seguidas de vários relatos de aplicação, verifica-se ainda poucos esforços nessa direção.

Um breve exame no setor de cursos voltados para o ensino-aprendizagem de Inglês para Fins Específicos, e, principalmente aqueles que se realizam em contextos acadêmicos, foco deste trabalho, revela 
que esse apelo ainda se faz pouco sentir, porquanto, no mercado ainda hoje proliferam em demasia cursos voltados para leitura de textos (conhecidos no Brasil como cursos de leitura instrumental) quase exclusivamente de cunho estratégico (cf.: Ramos 2005). Nesse sentido, ao fazer uma mudança do foco estratégico para priorizar o de gêneros, enveredar o trabalho para demonstrar como o planejamento de um curso faz uso de sua aplicação em sala de aula e, mais especificamente, para gêneros que muitos estudantes brasileiros necessitam ler em suas esferas acadêmicas, este artigo não só mostra outra possibilidade de se ofertar cursos nesse setor, mas pode também contribuir para o desenvolvimento de pesquisas na área.

O presente artigo objetiva, portanto, relatar a experiência de trazer para a prática pedagógica a utilização de gêneros escritos acadêmicos, apresentando o design e a implementação de um curso de compreensão escrita de Inglês para Fins Acadêmicos - IFA (correspondente à sigla inglesa EAP-English for Academic Purposes) -, e discutindo os problemas e as soluções encontrados nessa tarefa, decorrentes de avaliações e da utilização do material em sala de aula. O curso em questão foi desenhado e implementado por um grupo de pesquisadores (alguns também professores do curso em questão). $\mathrm{O}$ tema do trabalho integrou a pesquisa que se desenvolveu na Pontifícia Universidade Católica de São Paulo (PUCSP), junto ao grupo de pesquisa do Conselho Nacional de Desenvolvimento Científico e Tecnológico (CNPq) "Abordagem Instrumental e Ensino-Aprendizagem de Línguas para Contextos Diversos", denominado GEALIN.

Em linhas gerais, os pressupostos teóricos que embasam o trabatho apresentado baseiam-se na abordagem de ensino-aprendizagem de Inglês para Fins Específicos (Hutchinson e Waters 1987; Dudley-Evans e St John 1998), nos pressupostos teóricos sobre design de cursos de Graves (2000), nos conceitos de gênero de Martin (1984, 2000), Swales (1990), Bhatia $(1993,2004)$ e na proposta pedagógica de Ramos (2004). Esses pressupostos teóricos são apresentados no decorrer do artigo. Dessa forma, iniciando pela contextualização do curso, de seu histórico e pelas razões que conduziram a mudanças, apresentam-se as bases teóricas que nortearam o design do curso de compreensão escrita de Inglês para Fins Acadêmicos baseado em gêneros. Seguem também decisões quanto a sequenciamento de conteúdos, às bases teórico- 
metodológicas que guiaram a produção do material didático utilizado e alguns exemplos desse material. A seguir, comentam-se problemas e soluções encontrados nessa tarefa, decorrentes de avaliações e da utilização do material em sala de aula. Ao final, são feitas algumas considerações sobre essa experiência e desafios para o desenvolvimento de cursos voltados para o ensino-aprendizagem de Línguas para Fins Acadêmicos.

\section{Contextualização}

Para melhor situar este curso, é necessário que esse seja colocado em um contexto mais amplo. Suas origens derivam do Projeto Nacional Ensino de Inglês Instrumental em Universidades Brasileiras, que se desenvolveu no Brasil de 1978 a 1990, com coordenação nacional, na PUCSP. Como já relatado na literatura (Celani et. al. 1988; Celani et. al. 2005; Celani e Holmes 2006; Ramos 2005, 2009a), esse Projeto teve como base o desenvolvimento de formação de professores para implementar cursos de compreensão escrita. Decorrente desse trabalho, criou-se uma metodologia de ensino-aprendizagem de leitura que parte da compreensão geral de textos autênticos para níveis mais detalhados, priorizando a conscientização do processo de leitura, utilização de estratégias de leitura, uma gramática mínima do discurso (cf.: Deyes 1981), bem como outros. Foi nesse contexto, por conseguinte, que este curso nasceu.

Inicialmente, o curso foi produzido para ser ministrado no campus da PUCSP, como parte do trabalho de pesquisa do grupo (entre eles, esta pesquisadora) que naquele momento era encarregado do desenvolvimento dessa abordagem na instituição hospedeira do Projeto. O curso foi ministrado em uma primeira versão em 1983, por uma aluna que fazia seu mestrado nessa instituição e tinha pesquisa concentrada na área da abordagem instrumental. A partir de 1984, esta pesquisadora passou a ministrar esse curso e a pensar em possibilidades de desenvolvimento para ele, consubstanciadas no que será apresentado adiante.

\subsection{O histórico do curso e as razões de mudança}

O curso Inglês Instrumental: Leitura, como já indicado, era parte do 
grupo que estavam sediados na PUCSP, junto à coordenação do Projeto. Foi idealizado e aplicado inicialmente em 1983 para atender alunos dos mais diversos programas de pós-graduação, em sua maioria da própria universidade, cuja necessidade primária era compreender textos para auxiliar seus trabalhos em suas áreas de especificidade. Embora não fosse objetivo do curso, para muitos alunos uma das metas a ser alcançada por meio do curso era também passar no exame de proficiência em língua estrangeira, obrigatório para alunos de pós-graduação. A partir de 1986, o curso foi estruturado em dois níveis ( 1 e 2). O estabelecimento dos níveis era feito com base na concepção didática de níveis de compreensão de leitura (da geral, passando por pontos principais para detalhada). A proficiência linguística não era pré-requisito para o estabelecimento dos níveis (assumia-se que os alunos já haviam tido contato com a língua inglesa na educação básica). Cada nível possuía duração de 30 horas, com uma aula semanal de duas horas. Suas características eram as mesmas idealizadas pela metodologia do Projeto, descrita nas várias publicações feitas durante seu desenvolvimento (cf. http://www4.pucsp.br/pos/lael/cepril/workingpapers/), ou seja, seu conteúdo programático caracterizava-se como estratégico, trabalhava com textos autênticos, porém, na maioria de natureza diversa do mundo acadêmico. Além disso, tinha como fundamentos teóricos a concepção construtivista de ensino-aprendizagem (cf. Mizukami 1986; Williams e Burden 1997) e já possuía uma concepção funcional de linguagem, além de basear-se em uma perspectiva discursivo-textual.

Entretanto, as novas concepções de ensino-aprendizagem sociointeracionistas (Vigotski 1988, 1998; Rego 2002) que priorizam, entre outras características, as interações sociais como primordiais para a aprendizagem e, as de linguagem (Halliday e Hasan 1989; Halliday 1978, 1994; Halliday e Mathiessen 2004) que trazem à tona as concepções de língua como sistemas entrelaçados que organizam as opções de escolha que estão à disposição dos usuários, em um determinado contexto, como recurso para a construção de significados, bem como a noção de linguagem como prática social, passaram a acenar para mudanças no campo de ensino-aprendizagem. Além disso, noções relacionadas às teorias de gênero que o compreendem como configurações de significados recorrentes e pelas quais o homem em sociedade desempenha as mais variadas práticas sociais de uma cultura (cf.: Martin e Rose 2008: 6) também trouxeram mudanças para o campo 
educacional. Reconhece-se que são os gêneros, com suas diferentes formas textuais, propósitos comunicativos diversos, entre outros, que possibilitam aos indivíduos interagirem por meio das mais variadas formas de comunicação em sociedade. Em outras palavras, o gênero, definido como "um processo social dinâmico, com um ou mais propósitos comunicativos, altamente estruturado e convencionalizado, reconhecido e mutuamente compreendido pelos membros da comunidade em que ele rotineiramente ocorre" e tendo-se a compreensão de "que ele opera não só dentro de um espaço textual mas discursivo, tático (estratégico) e sócio-cultural" (Ramos 2004: 115), passa a predominar nos estudos da área e a alavancar um conhecimento cada vez mais avançado e a chamar por uma pedagogia baseada em gêneros.

Foi, portanto, esse avanço no campo do conhecimento e das pesquisas (Ramos; Lima-Lopes e Gazotti-Vallim 2004, por exemplo), entre outros, que motivou a procura de novos caminhos para a aprendizagem dos alunos que buscavam esse curso. Por abraçar essa nova concepção e acreditar que gêneros textuais podem ser "um recurso pedagógico poderoso" (Ramos 2004: 116) "e reconhecer que a implementação dessa concepção em sala de aula pode contribuir para reflexões sobre como utilizar as noções teóricas em aplicações para seu uso em sala de aula de língua estrangeira" (Ramos 2012: 65), é que partiu-se para um novo projeto para esse curso.

Como os alicerces teóricos do curso se baseiam nos princípios da Abordagem Instrumental ou Ensino-Aprendizagem de Línguas para Fins Específicos (Hutchinson e Waters 1987; Strevens 1988; DudleyEvans e St John 1998, para citar alguns), cuja mola motriz para o design de cursos são as necessidades dos alunos, o primeiro passo para que esse curso pudesse ser redesenhado foi conduzir uma análise de necessidades junto aos alunos desse curso, componente essencial de um design de curso baseado nessa abordagem (cf.: Hutchinson e Waters 1987).

Consequentemente, a primeira etapa desse trabalho, já detalhadamente relatada em Ramos; Lima-Lopes, Gazotti-Vallim. (2004), foi fazer um levantamento com os alunos de suas necessidades em relação a sua situação-alvo (Hutchinson e Waters 1987), quais gêneros acadêmicos esses alunos precisariam fazer uso em seus cursos e 
também questões relacionadas às necessidades de aprendizagem (cf.: Hutchinson e Waters, 1987) e nesse caso, questões relativas à habilidade comunicativa de compreensão escrita, foco do curso.

Como o interesse deste trabalho são os gêneros acadêmicos, reproduz-se abaixo o quadro extraído de Ramos; Lima-Lopes, GazottiVallim (2004: 15) que mostra os gêneros indicados como os mais lidos/ frequentes durante os três semestres em que a coleta foi realizada.

Quadro 1 - Gêneros indicados com relação à frequência de leitura nas três coletas

\begin{tabular}{|l|l|l|}
\hline $1^{\mathrm{a}}$ coleta (1999) & $2^{\mathrm{a}}$ coleta (2000) & $3^{\mathrm{a}}$ coleta (2000) \\
\hline 1. Artigo acadêmico & 1. Resenha de artigo & $\begin{array}{l}\text { 1. } \text { Abstract, } \text { artigo } \\
\text { acadêmico }\end{array}$ \\
\hline 2. Capítulo de livro & $\begin{array}{l}\text { 2. } \text { Abstract e introdução de } \\
\text { artigo acadêmico }\end{array}$ & $\begin{array}{l}\text { 2. Introdução de artigo } \\
\text { acadêmico }\end{array}$ \\
\hline $\begin{array}{l}\text { 3. Introdução de artigo } \\
\text { acadêmico }\end{array}$ & 3. Artigo acadêmico & 3. Prefácio de livro \\
\hline $\begin{array}{l}\text { 4.Conclusão(Artigo } \\
\text { acadêmico), abstracts }\end{array}$ & $\begin{array}{l}\text { 4. Relatório/relato de } \\
\text { pesquisa, prefácio de livro, } \\
\text { conclusão de artigo }\end{array}$ & $\begin{array}{l}\text { 4. Conclusão (artigo } \\
\text { acadêmico) }\end{array}$ \\
\hline $\begin{array}{l}\text { 5. Prefácio de livro, } \\
\text { resenha de livro }\end{array}$ & 5. Capítulo de livro & 5. Capítulo de livro \\
\hline
\end{tabular}

O quadro 1 dá uma visão de quais gêneros foram selecionados para compor o novo conteúdo programático (syllabus) do curso. Os gêneros escolhidos foram: (a) o artigo acadêmico (indicado como publicação de periódicos na coleta de dados); (b) o relato de pesquisa, bem como suas partes - introdução e/ou conclusão - indicadas na coleta separadamente; (c) a resenha; (d) o abstract; (e) o prefácio. Esses resultados, consequentemente, compuseram a escolha dos gêneros que poderiam ser incorporados ao design e reelaboração do curso vigente, assim como constituíram parte do primeiro componente do design, ou seja, a análise de necessidades, como indicado adiante.

\section{O design do curso e suas bases teóricas}

O curso foi projetado, seguindo os conceitos teóricos da abordagem de ensino-aprendizagem de Línguas para Fins Específicos - ter por ob- 
jetivo possibilitar ao aluno desempenhar tarefas nos contextos nos quais fará uso da língua que está aprendendo. Para isso, seu planejamento foi feito com base nas necessidades identificadas por meio da análise de necessidades (cf.: Hutchinson e Waters 1987; Dudley-Evans e St John 1998; Long 2005). Com base nessas premissas, esse curso teve como objetivos: capacitar o aluno a trabalhar com os gêneros escritos necessários ao contexto acadêmico no qual ele se insere; desenvolver sua competência leitora em inglês; desenvolver habilidades de estudo (usar o dicionário, tomar notas, resumir etc.) voltadas para o contexto acadêmico. Essas finalidades e características o identificam como um curso de IFA (cf. Jordan, 1997). Com isso, seu nome passou a ser Inglês Instrumental: Leitura para Fins Acadêmicos.

É importante também que um curso se fundamente em concepções de ensino-aprendizagem e de linguagem, pois são essas bases que nortearão as escolhas que serão feitas em relação ao conteúdo a ser ensinado e ao como esse conteúdo será trabalhado para que se propicie a aprendizagem. Portanto, seguindo esses princípios, o curso tomou como base as visões de ensino-aprendizagem e linguagem sociointeracionistas vigentes no contexto educacional nacional.

Além disso, alguns dos parâmetros apontados em Dudley-Evans e St John (1998) como necessários para o design de um curso também foram incorporados a esse curso: atender necessidades imediatas (caso do curso) ou futuras; ter um foco amplo ou limitado (esse curso); utilizar material específico da área em que o aluno atua/atuará ou material relacionado a conteúdo acadêmico; ser fixo ou flexível; ter o professor como facilitador, mediador ou provedor de insumos (também presentes no curso).

Embora não trabalhando diretamente com a área, Graves (2000) foi também considerada para este trabalho, já que a autora não considera o design de cursos um processo linear no qual os componentes denominados análise de necessidades, objetivos, conteúdo, elaboração de materiais, aplicação, avaliação acontecem sequencialmente, mas sim um processo multifacetado no qual não há uma hierarquia e nem tampouco uma sequência fixa a ser seguida. Em outras palavras, o design de um curso funciona como um sistema, no qual ao planejar-se um dos componentes essa escolha ajuda e/ou afeta os demais. A figura 1 abaixo, 
extraída de Graves (2000: 3), ilustra os processos/componentes envolvidos no design de um curso - análise de necessidades, formulação de objetivos e metas, desenvolvimento de materiais, desenho de um plano de avaliação, organização do curso e conceptualização do conteúdo - no qual a autora acrescenta dois outros elementos que sempre o ancoram, a definição do contexto (defining the context), ou seja, lugar, tempo e condições em que o curso ocorre/ocorrerá e a articulação de crenças (articulating beliefs), mostrados no primeiro círculo do sistema.

Figura 1 - Modelo de processos de desenvolvimento de cursos

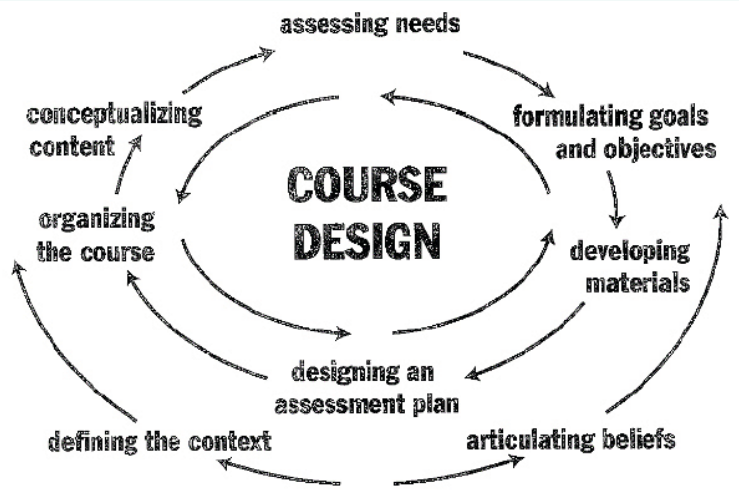

Fonte: Extraído de Graves (2000: 3)

Essa base teórica veio ao encontro das crenças do grupo, uma vez que esse também acredita que desenhar um curso é "um trabalho em andamento" (Graves 2000:7). Para Graves (2000), o ciclo de desenvolvimento de um curso acontece em quatro fases (ciclos). A fase do planejamento, denominada por Graves (2000: 9) de Conceptualização, envolve desde o levantamento de necessidades até o início do curso propriamente dito; a segunda fase é a Prática, isto é, o oferecimento das aulas; a terceira fase é Reconceptualização a qual se baseia no que se aprendeu oferecendo as aulas; e, a quarta fase seria a volta à Prática novamente e assim continuamente. É preciso pontuar que Graves (2000: 10) destaca que a primeira fase continua a acontecer simultaneamente com a segunda fase, pois a prática não é apenas uma questão de aplicar o planejamento, mas remodelá-lo continuamente e, portanto, avaliação e tomada de decisões são componentes onipresentes durante todo o ciclo. 
Também tomou-se como fundamento algumas considerações feitas por Dudley- Evans e St John (1998: 169) em prol de auxiliar professores quando se defrontam com a tarefa de desenhar seus próprios cursos: ter a capacidade de adaptar. Nas palavras desses autores, o professor pode economizar tempo e energia, observando decisões tomadas e materiais escolhidos em outros cursos para fazer adaptações desses elementos de modo a combinar com os parâmetros especificados para seu próprio curso. Como será visto adiante, esse fundamento aparece nas decisões que foram tomadas para redesenhar o novo curso.

É importante salientar que esta fase foi também um desafio para o grupo, pois elaborar materiais é uma tarefa árdua, como já apontado em vários trabalhos na literatura que se dedicam ao desenvolvimento de materiais didáticos. Como bem pontua Tomlinson (2003a: 4), a produção de materiais demanda um longo período de tempo, uma vez que, entre outras razões, a revisão e a testagem desses materiais são também fases importantes desse processo. Já no caso da elaboração por este grupo, esse trabalho contou ainda com outros desafios, porque envolveu o desenvolvimento de conhecimentos vários entre os pesquisadores-professores, a saber: aspectos teóricos dos princípios trabalhados, conhecimentos de designer (por exemplo, layout do material, tipologia de atividades, a linguagem das instruções etc.) e conhecimentos que envolvem a análise de textos (gêneros). Logo, a concepção de tomá-lo como sistema (não sequencial, multifacetado, em andamento etc.) adequa-se perfeitamente a ele.

Outro elemento que compôs a fase Conceptualização desse design foi a adoção da proposta pedagógica de aplicação de gêneros em sala de aula de Ramos $(2000,2004)$ para a elaboração das unidades. A autora acredita que esse trabalho proporciona realizar tarefas em sala de aula que se tornam socialmente relevantes, uma vez que a língua-alvo é utilizada em uma situação real na qual "os conhecimentos linguístico, genérico e social são construídos” (Ramos 2004: 126).

Essa proposta apresenta um plano de trabalho com gêneros a ser executado em três fases: Apresentação, Detalhamento e Aplicação, ou seja, inicia-se com exposição geral do conteúdo para uma mais específica, em uma perspectiva espiralada que pode garantir que o aluno não se aproprie de conhecimentos sobre um determinado gênero de modo compartimentalizado (cf.: Ramos 2004). Outro ponto relevante, 
apontado por Ramos (2004), é que para a aplicação dessa proposta é necessário que se analisem previamente os gêneros a serem trabalhados em sala pelo professor, para que ele possa identificar os aspectos peculiares desse gênero que serão posteriormente contemplados na elaboração do material que comporá o curso.

Consequentemente, esse trabalho com gêneros objetiva, conforme Ramos (2004: 116-117): conscientizar o aluno da estrutura e propósito dos gêneros diferentes, assim como de características linguísticas e socioculturais; proporcionar o conhecimento de textos como construção linguística, social e significativa com vistas ao desenvolvimento crítico do uso dos gêneros em sociedade; conhecer as formas textuais e seus processos de construção; capacitar a usar estratégias necessárias para replicar essas características na sua própria produção. Para a execução desses objetivos, a autora sugere que as atividades, além desses, também possam garantir que os alunos percebam que as estruturas de um gênero não são prescritivas e possuem variações tanto de ordem cultural como individual, permitindo ao aluno apropriações criativas e que também percebam propósitos, audiência, estrutura, as crenças e valores institucionais envolvidos na sua construção de modo a propiciar uma visão crítica sobre seus usos.

Desse modo, as atividades/unidades da primeira fase, Apresentação, implicam conscientização e/ou familiarização com o gênero estudado. São explorados aspectos relacionados ao contexto de situação e de cultura (Halliday e Hasan 1989; Halliday 1994) nos quais o gênero circula, quem são seus usuários, relações entre participantes, conteúdos e propósitos, a que interesses, grupos serve etc.

Atividades da segunda fase, Detalhamento, envolvem tanto o trabalho com o gênero em uma perspectiva mais ampla como aspectos mais peculiares do gênero: sua organização retórica (estrutura), suas características léxico-gramaticais, com o objetivo de conduzir o aluno a utilizar e vivenciar esses componentes na prática.

Na terceira fase, Aplicação, as atividades devem articular o trabalho feito nas duas fases anteriores, de modo a reintegrar os conhecimentos adquiridos anteriormente. A autora reputa essa fase a mais importante no trabalho com o gênero, pois é nesse momento que se espera que o aluno consolide sua aprendizagem e se aproprie do gênero em questão. 
Foram, portanto, essas concepções que alicerçaram a construção das unidades didáticas que trabalhavam com os gêneros escolhidos.

\subsection{Desenvolvimento do curso: Conceptualização e Prática}

Os próximos passos, ainda na fase Conceptualização, com a participação dos membros do grupo envolvidos com o curso, foram um exame e discussão dos conteúdos anteriores, bem como escolhas sobre quais gêneros identificados na análise de necessidades comporiam o curso.

Esse exame e discussão levaram a fazer uma seleção de itens dos conteúdos programáticos (syllabuses) anteriores relativos aos conteúdos estratégicos e elementos léxico-gramaticais que os compunham e que foram julgados pelo grupo como importantes de serem mantidos. Assim, foram escolhidos aqueles considerados relevantes para serem adaptados e trabalhados no novo curso.

Já em relação aos gêneros escolhidos para serem trabalhados, verificou-se que alguns deles careciam de descrições na literatura e por isso demandaram um trabalho mais exaustivo. Seguindo os preceitos metodológicos de Swales (1990) e Bhatia (1993), foi preciso fazer primeiramente uma análise descritiva desses gêneros para que então pudesse ser feita uma análise, conforme sugerida em Ramos (2004), para a produção das atividades/unidades didáticas. São eles o prefácio (Fischer e Gazotti-Vallim 2000) e o artigo teórico (em geral, aqueles publicados como capítulos de livro) assim denominado pelo grupo por falta de um nome consagrado para ele (Farias e Ventura 2002; Fischer, Ventura, Farias e Weyersbach 2001a, 2001b; Ventura e Farias 2002).

Uma vez realizadas a análise e a seleção dos conteúdos programáticos - agora inclusive abarcando gêneros -, passou-se a discutir o sequenciamento desses e a definição do padrão das unidades. Uma nova divisão de trabalho entre os membros do grupo foi feita. A elaboração das unidades foi dividida entre os participantes para posterior discussão e revisão por todos os integrantes do grupo para que se pudesse também chegar a uma padronização da elaboração das anotações para o professor, denominadas pelo grupo de teacher's notes (anotações do 
professor) e das próprias unidades didáticas. Esse cuidado foi importante, pois assegurou que todos os envolvidos no processo de ministrar as aulas pudessem comungar uma certa coerência no "como" o material didático poderia ser trabalhado em sala de aula pelos diferentes professores e mesmo por aqueles que não tivessem participado desse desenvolvimento, mas viriam a ministrar esse curso no futuro.

Essas tarefas geraram os conteúdos programáticos para o novo curso, ilustrados nos quadros 2 e 3.

Quadro 2 - Conteúdo programático do nível 1

\section{Nível 1 - Conteúdos}

- 'Conscientização' sobre o processo de leitura

- Níveis de compreensão

- Estratégias de leitura (predicão, skimming e scanning, etc.)

- Grupos nominais

- Exercício padrão para compreensão de textos

- Habilidades de estudo: uso do dicionário, esquemas de anotações de leitura

- Familiarização com gêneros acadêmicos

- Prefácios

- Artigo de pesquisa e algumas características léxico-gramaticais

Como observado no quadro acima, os conteúdos foram sequenciados inicialmente para focalizar prioritariamente conteúdos estratégicos, pois, por avaliação do grupo e dos professores que ministravam o curso, esses se mostraram ao longo dos anos altamente importantes e de sucesso para o desenvolvimento da competência leitora dos alunos e, por conseguinte, não deveriam ser abandonados no novo planejamento. Portanto, o Nível 1 inicia-se com foco em conteúdos estratégicos para paulatinamente ir mudando para aqueles baseados em gênero, observado no quadro 1 com o conteúdo sinalizado no item "Familiarizacão com gêneros textuais", e paulatinamente passando a privilegiar os gêneros selecionados.

É importante também salientar que os conteúdos programáticos foram planejados em unidades didáticas divididas em aulas. Por exemplo, a unidade didática 1 , denominada "Conscientização do processo de leitura" foi planejada para uma sequência de aulas (4 aulas de 2 horas cada), trazendo para os alunos várias atividades que envolvem 
a conscientização desse processo e elementos estratégicos e linguísticos ligados a ele, por exemplo, estratégias como predição, skimming, scanning, uso do contexto para inferência lexical, inferência, conhecimento de vocabulário prévio, níveis de compreensão de leitura, grupos nominais etc.

Quadro 3 - Conteúdo programático do nível 2

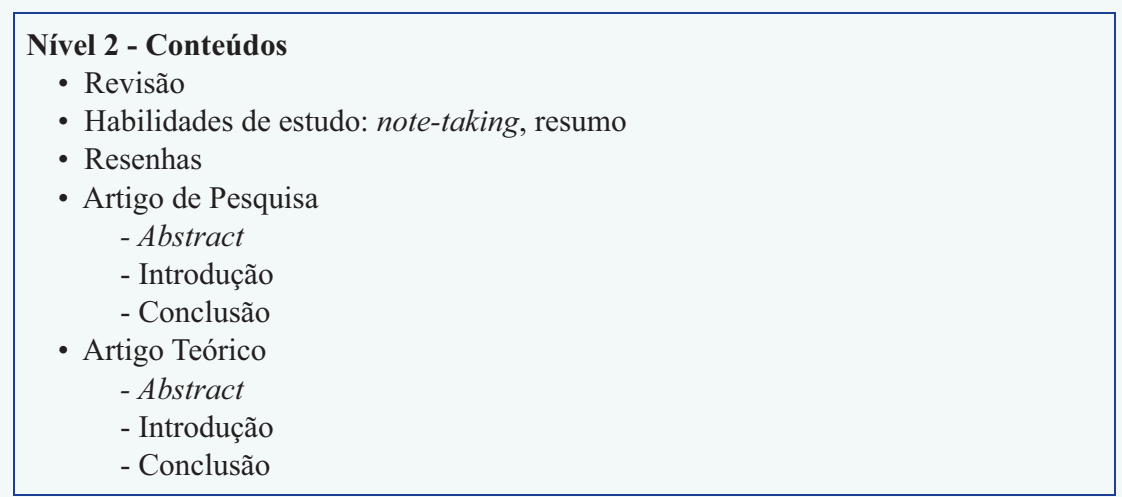

O conteúdo do Nível 2, como pode ser observado no quadro 3 acima, faz uma retomada dos conteúdos estudados no Nível 1 e agrega novos conteúdos ao item habilidades de estudo (note-taking e resumo). Os demais itens já são elencados por gêneros e trabalhados fundamentado na proposta pedagógica de Ramos (2004). É necessário esclarecer também que para as unidades didáticas planejadas com os gêneros artigo de pesquisa e artigo teórico, esses foram trabalhados inicialmente na sua íntegra para em seguida dar-se atenção especial aos subitens indicados no quadro 3. Essa atenção especial deve-se ao levantamento de necessidades feito anteriormente que identificou esses componentes da estrutura de cada um desses gêneros (abstract, introdução conclusão para o gênero artigo de pesquisa e abstract, introdução e conclusão para o gênero artigo teórico) como os mais lidos e necessários para os alunos.

A seguir mostram-se exemplos desse material, apresentando duas atividades usadas no curso. Os textos não são mostrados por motivos de sua extensão e porque para este propósito sua exibição não se faz imprescindível para seu entendimento. 
Quadro 4 - Exemplo1 de atividade

\section{Exemplo 1 \\ The ESPecialist, São Paulo, vol. 24, nº 1 17-34}

The Use of English in Hotels in Sorocaba and Surrounding Cities: a study on the target situation needs

Luiz Fernando GOMES (UNISO- Universidade de Sorocaba)

\section{NONONO}

Nononononononononononononononononononononononononononononononononononononononononononononononononononononononononononononononononononononononononononononononononononononononononononononononononono.

Key-words: nononononono; nononononono; nonononononono.

a) Que gênero textual é este?

b) Qual o assunto do texto?

c) Escreva pelo menos cinco itens ou tópicos que poderão ser abordados no texto

d) Liste cinco outras palavras (em português ou inglês) que estão relacionadas ao assunto abordado.

Observe-se que a atividade ilustrada no quadro 4 exemplifica a fase de Apresentação, na qual é feito um trabalho de conscientização sobre o gênero abstract e ao mesmo tempo trabalha-se com habilidades de compreensão leitora, a saber: predição, conhecimento do léxico relativo ao conteúdo e tópicos do texto.

Já no exemplo do quadro 5, a seguir, a atividade também ilustra a fase Apresentação, porém caminhando para a fase Detalhamento. Nessa atividade o aluno precisará explorar vários elementos do gênero, tais como, lugar de circulação, propósitos, conteúdos, elementos da estrutura textual.

Quadro 5 - Exemplo 2 de atividade

\section{Exemplo 2}

Atividade 3 - Agora você vai trabalhar com um gênero textual específico, que circula no mundo acadêmico - o relato de pesquisa.

Observe os próximos dois textos ( $\mathbf{C}$ e $\mathbf{D})$. Ambos são exemplares do gênero relato de pesquisa. Identifique o máximo de elementos comuns a ambos e anote a resposta na página $\mathrm{xx}$.

No próximo exemplo, quadro 6, são apresentadas atividades extraídas da unidade didática que trabalha com o gênero abstract . Como pode ser observado, nessa aula incentiva-se o aluno a fazer um trabalho 
de conscientização sobre esse assunto. Em outras palavras, trabalhamse conteúdos relativos ao contexto de situação e de cultura do gênero (Halliday e Hasan 1989; Halliday 1994), além de audiência e também sobre questões de propósitos, entre outros. Mais adiante, depois de executar trabalhos com abstract e discutir com os alunos a estrutura textual desse gênero, o aluno passa a trabalhar com os movimentos de sua estrutura (Swales 1990) e também é chamado a identificar elementos léxico-gramaticais que sinalizam os movimentos.

No exemplo 3, a seguir, só é mostrada parte da atividade toda, ou seja, o aluno deverá fazer o mesmo tipo de trabalho com cada movimento do abstract, denominada para os alunos "parte", uma das decisões tomadas, quando da elaboração, em relação ao uso de nomenclatura teórica com os alunos.

Quadro 6 - Exemplo 3 de atividade

\section{Exemplo 3}

Atividade 2: Observe no quadro acima que os artigos geralmente se iniciam com abstracts. O que você sabe sobre eles?

a. Quem os escreve?

b. Quem os lê?

c. Qual seu propósito no artigo?

d. Por que as pessoas os leem ou escrevem?

e. Em que outros locais eles são publicados?

Atividade 4: Leia os abstracts de 1 a 5 e preencha o quadro a seguir, identificando suas partes, lembre que alguns textos podem não conter todos os elementos.

\begin{tabular}{|c|c|c|c|c|c|}
\hline Partes & Abstract 1 & Abstract 2 & Abstract 3 & Abstract 4 & Abstract 5 \\
\hline $\begin{array}{l}\text { Problema/ } \\
\text { Contextua- } \\
\text { lização }\end{array}$ & $\begin{array}{l}\text { ( ) Sim ( ) Não } \\
\text { Palavras/ } \\
\text { Expressões } \\
\text { que o } \\
\text { ajudaram: }\end{array}$ & $\begin{array}{l}\text { ( ) Sim ( ) Não } \\
\text { Palavras/ } \\
\text { Expressões } \\
\text { que o } \\
\text { ajudaram: }\end{array}$ & $\begin{array}{l}\text { ( ) Sim ( ) Não } \\
\text { Palavras/ } \\
\text { Expressões } \\
\text { que o } \\
\text { ajudaram: }\end{array}$ & $\begin{array}{l}\text { ( ) Sim ( ) Não } \\
\text { Palavras/ } \\
\text { Expressões } \\
\text { que o } \\
\text { ajudaram: }\end{array}$ & $\begin{array}{l}\text { ( ) Sim ( ) Não } \\
\text { Palavras/ } \\
\text { Expressões } \\
\text { que o } \\
\text { ajudaram: }\end{array}$ \\
\hline
\end{tabular}


Importante assinalar que esse novo curso passou a ser oferecido pela primeira vez em 2004, inicialmente com algumas unidades que foram se agregando ao curso existente com o intuito de pilotar esse material e também possibilitar aos professores que ministravam as aulas se adaptarem a esses novos conteúdos, gerando assim avaliações a respeito do material. Nos anos seguintes, o Nível 2 foi totalmente reformulado e as mudanças para o que foi apresentado nos quadros 2 e 3 acima, no que se refere aos novos conteúdos programáticos foram implementadas.

Uma vez exposta a fase Conceptualização (cf.: Graves 2000) e indicada a Prática, apresenta-se a Reconceptualização: aquilo que se aprendeu decorrente da Prática (oferecimento das aulas).

\subsection{Reconceptualização}

Seguem os resultados das avaliações feitas pelos professores (observações de sala de aula, avaliação informal no fim de cada nível, pré-teste e pós-teste) que ministravam esse curso, do material produzido e aplicado e das discussões em grupo (que aconteciam mensalmente). Neste caso específico, incorporou-se ao design o componente avaliação: por um lado, avaliação advinda do que Tomlinson (2003b: 23-28) denomina "durante o curso" (whilst-use evaluation) e pós-uso (postuse evaluation); por outro lado, avaliação do material didático pelo material didático, denominada na "perspectiva do material" (Ramos 2009b: 182).

Considerando os resultados obtidos junto aos alunos, constatou-se nas avaliações de final de curso feitas informalmente com os alunos que esses, de modo geral, ficaram bastante satisfeitos com o curso. Além disso, os resultados do pré-teste e pós-teste que foram aplicados aos alunos indicaram que houve um progresso grande em relação ao desenvolvimento das habilidades de compreensão escrita e também no desempenho deles em relação ao nível de compreensão, que ao iniciar o curso na média geral era de compreensão geral do texto e ao final chegaram a entender os textos em nível de compreensão de pontos principais e mais adiante, alguns conseguiram em nível de compreensão detalhada (observado com alunos do Nível 2). Em relação aos gêneros, 
os alunos indicaram ter aprendido a reconhecer os gêneros com as quais trabalharam e ser capazes de identificar agora propósitos, audiência, circulação, bem como outros componentes, com maior presteza. Além disso, muitos indicaram que aprenderam a reconhecer a estrutura textual dos gêneros apreendidos e alguns elementos léxico- gramaticais que marcam os gêneros estudados.

Outro resultado decorrente das observações dos professores em sala de aula é que os gêneros inicialmente indicados na análise de necessidades e escolhidos para comporem os conteúdos programáticos precisariam ser revistos, uma vez que ao se conversar com as turmas para as quais o curso era ministrado, verificou-se que prefácio e resenhas não faziam parte das necessidades da situação alvo dos alunos. Esses gêneros foram, por essa razão, eliminados dos conteúdos programáticos iniciais.

Um outro resultado, decorrente do oferecimento das aulas e também da avaliação feita pelos participantes do grupo de pesquisa das unidades novas ou mesmo remodeladas, foi verificar que as instruções do material elaborado para os alunos necessitavam de direções mais claras para sua execução. O mesmo problema foi também identificado na elaboração das anotações para o professor (teacher's notes). No caso desse material, foi necessário que muitos dos procedimentos descritos para auxiliar o professor na apresentação do material para os alunos fossem refeitos e reestruturados por falta de clareza e entendimento comum para quem o lesse, ou mesmo das explicações sobre o embasamento teórico dos porquês utilizar o material desta ou daquela forma.

Outro achado resultante dessa avaliação foi a constatação de que as áreas de especialidade precisavam ser revistas, dado que os exemplos de gêneros trabalhados quase que em sua maioria provinham da área médica ou da saúde, trazendo reclamações dos alunos para o curso. Essa escolha encontra justificativa na fase Conceptualização do design, pois quando da elaboração do material, o grupo defrontou-se com dificuldades em encontrar textos que pudessem mais claramente explicitar as características proeminentes (típicas) de um determinado gênero para os objetivos de aplicação, optando, então por trabalhar com textos que naquele momento pudessem mais rapidamente ajudar a agilização da elaboração do material. Por ter gerado um problema durante sua aplicação, foi preciso encaminhar o trabalho para novos 
fazeres, o que significou fazer uma nova seleção de textos que ilustrassem os gêneros a ser trabalhados, oriundos das diversas áreas das quais os alunos procediam.

Dois últimos resultados que merecem destaque são questões relacionadas aos conteúdos programáticos vigentes nos dois Níveis. Decorrente das avaliações dos professores durante a aplicação do material e também da avaliação do material, um primeiro indicou que o curso como um todo, apesar de utilizar gêneros com êxito, ainda se mostrava bastante calcado no ensino-aprendizagem de estratégias. O segundo mostrou que a passagem do conteúdo estratégico não se fazia de modo gradual, mas sim de modo abrupto, tornando a concepção de espiral que se desejava na Conceptualização estanque. Esses resultados, portanto, geraram novos desafios para o desenvolvimento do curso, fazendo com que o grupo novamente se voltasse para a fase Conceptualização do curso.

\section{Considerações finais}

Neste artigo apresentou-se uma experiência que esta pesquisadora juntamente com o grupo de pesquisa desenvolveu com o ensino-aprendizagem de gêneros textuais em um curso de compreensão escrita de IFA para alunos de pós-graduação que precisam mais especificamente desenvolver a competência leitora em língua inglesa. Essa experiência mostrou a todos envolvidos nesse processo que esta foi uma experiência bem sucedida, posto que essa provou durante esses anos em que foi implementada, que trabalhar com gêneros é uma tarefa gratificante, pois demonstrou que a aprendizagem por meio de gêneros é frutífera em termos de aprendizado da competência leitora, agregando um conhecimento de língua que não compartimentaliza conteúdos gramática, vocabulário e estrutura, por exemplo -, mas faz com que esses componentes linguísticos se amalgamem para formar um todo coerente, possibilitando os alunos a agir linguística e socialmente em seus contextos específicos em língua inglesa.

Nesse sentido, é importante que cursos de Inglês para Fins Específicos no Brasil, especialmente aqueles voltados para o desenvolvimento da competência leitora baseados primordialmente em estratégias e 
textos mais gerais, considerem a experiência vivenciada por este curso para também pensarem em mudanças. Ou seja, mudar seu foco de estratégico, como estabelecido no país há algumas décadas, para o de gêneros. Além disso, observar que nos novos contextos acadêmicos há mudanças em relação aos gêneros que neles circulam e às demandas de novas tarefas que precisam ser desempenhadas pelos alunos e profissionais nesses contextos. Isso, com certeza trará mudanças para a própria denominação dos cursos que ainda hoje utilizam a denominação mais genérica ou abrangente de ESP (English for Specific Purposes), para uma melhor especificação da área em que de fato se insere - IFA -, ou seja, cursos voltados para aqueles que precisam desempenhar tarefas específicas em contextos acadêmicos. Essas mudanças, com certeza, poderão trazer não só novos ares para esses cursos, como poderão também trazer resultados mais efetivos para o desempenho de seu público em seus contextos específicos.

Como dito inicialmente, este é um curso que se acredita está em "andamento" e, como consequência, novas ações decorrentes da Reconceptualização despontam para um trabalho como esse.

Primeiro, por razões do próprio entendimento da concepção de gêneros, que hoje passa a ser entendido, entre outros, como redes interconectadas (Swales e Feak 2009), novas questões se colocam: Como desenvolver um trabalho que possa trazer os diversos gêneros que tramitam no contexto acadêmico, como teses, dissertações, relatórios, projetos, conferências e outros mais, e mostrar para os alunos como eles se interconectam em seus contextos de atuação, ao invés de apresentálos separadamente? Como integrar as tecnologias e o aprendizado de gêneros para uma geração que hoje já vive em uma sociedade em rede e que são usuários em seus contextos acadêmicos dos novos gêneros que emergem com esses novos meios de interagir e comunicar-se em sociedade? Como fazer uma integração entre estratégias e gêneros de modo que eles se mesclem e possam ser sequenciados em um novo conteúdo programático?

Essas questões são, pois, aquelas que neste momento se constituem a força motriz que impulsiona a busca de novos caminhos de pesquisa que precisam ser percorridos. 
Agradecimentos: Aos meus colegas do grupo GEALIN que colaboraram para a realização deste trabalho: Angélica Miyuki Farias, Carolina Siqueira Muniz Ventura, Cynthia Regina Fischer, Laura Vigia Dias, Márcia Bonamin, Maria Aparecida Gazotti-Vallim, Renata Ribeiro de Andrade Luvisotto Furtado, Rodrigo Lima-Lopes, Scheyla Riyadh Weyersbach, Zélia Cemin Cardoso.

Recebido em: 01 de outubro de 2014 Aprovado em: 01 de outubro de 2015 E-mail: rramos1@uol.com.br

\section{Referências bibliográficas}

Bazerman, Charles. 2006. Gênero, agência e escrita. Organização Judith Hoffnagel e Angela P. Dionísio. Tradução e adaptação Judith Hoffnagel. São Paulo: Cortez.

. 2005. Gêneros textuais tipificação e Interação. Organização Judith Hoffnagel e Angela P. Dionísio. Revisão técnica Ana Regina Vieira et al. São Paulo: Cortez.

BнатіA, Vijay. K. 1993. Analysing genre: language use in professional settings. London: Longman.

2004. Worlds of written discourse: a genre-based view. London: Continuum.

BRASIL. 1998. Parâmetros Curriculares Nacionais: terceiro e quarto ciclos do ensino fundamental - Língua Estrangeira. Brasília, MEC/SEF.

. 1999. Parâmetros Curriculares Nacionais (Ensino Médio). Parte

II - Linguagens, Códigos e suas Tecnologias. Brasília, MEC/SEF.

Celani, Maria Antonieta Alba; et al. 1988. The Brazilian ESP Project: an Evaluation. São Paulo: Educ.

et al. 2005. ESP in Brazil: 25 years of evolution and reflection.

São Paulo: EDUC/Mercado de Letras.

; Holmes, John. 2006. Sustainability and local knowledge: the case of the Brazilian ESP Project 1980 - 2005. English for Specific Purposes. 25(1): 109-122.

Deyes, Tom. 1981. Applications of Discourse Analysis.Towards a Minimum Discourse Grammar. Working paper n. 3 CEPRIL-LAEL/PUC- SP.

Dionísio, Angela Paiva; Machado, Anna Rachel; Bezerra, Maria Auxiliadora. (org.). 2002. Gêneros textuais e Ensino. Rio de Janeiro: Lucerna. 
DudLEy-Evans, Tony. 1987. Genre Analysis and ESP. ELR Journal. (1). Birmingham: ELR.

Dudley-Evans, Tony; St John, Maggie Jo. 1998. Developments in English for specific purposes: a multi-disciplinary approach. Cambridge: Cambridge University Press.

Farias, Angélica Miyuki; Ventura, Carolina Siqueira M. 2002. Proposta de Implementação do Gênero Artigo Teórico na sala de aula de leitura em inglês. Comunicação apresentada no $12^{\circ}$ InPLA, LAEL, PUC-SP, 25 a 27 de abril.

Fischer, Cynthia Regina; Gazotti-Vallim, Maria Aparecida. 2000. Resenhas acadêmicas de livros: um estudo de caso. Comunicação apresentada no $12^{\circ}$ InPLA, LAEL, PUC-SP, 25 a 27 de abril.

Fischer, Cynthia Regina; et al. 2001a. Descrição do gênero artigo teórico para posterior aplicação na sala de aula de leitura em inglês. $11^{\circ} \mathrm{InPLA}$, LAEL, PUC-SP, 4 e 5 de maio.

et al. 2001b. Artigo Teórico: descrição de um gênero como etapa para aplicação em sala de aula. Comunicação apresentada no $X V$ Seminário Nacional do Projeto Ensino de Inglês Instrumental em Universidades e Escolas Técnicas Brasileiras e III Seminário Nacional de Línguas Instrumentais. Universidade Estadual de Santa Cruz, 10 a 14 de setembro.

Graves, Kathleen. 2000. Designing Language Courses: a guide for teachers. Londres: Heinle \& Heinle.

JORDAN, R. R. 1997. English for academic purposes: A guide and resource book for teachers. New York: Cambridge University Press.

Halliday, Michael Alexander Kirkwood. 1994. An introduction to functional grammar. London: Edward Arnold. 1978. Language as social semiotic. London: Edward Arnold.

; Hasan, Ruqaiya. 1989. Language, context, and text: aspect of language in a social-semiotic perspective. Oxford: Oxford University Press.

Halliday, Michael Alexander Kirkwood; Mathiessen, Christian M. I. M. 2004. An introduction to functional grammar. London: Edward Arnold.

Long, Michael H. 2005. Second Language Needs Analysis. Cambridge: Cambridge University Press.

Hutchinson, Tom; Waters, Alan. 1987. English for specific purposes: a learning-centered approach. Cambridge: Cambridge University Press.

Marcuschi, Luis Antônio. 2008. Produção textual, análise de gêneros e compreensão. São Paulo: Parábola Editorial. 
MARTin, Jim R. 2000. Grammar meets genre: Reflections on the Sydney School. Inaugural Lecture at Sydney University Arts Association. 31 de agosto.

. 1984. Language, register and genre. In: Christie, F. (ed.). Children writing: reader. Geelong, Vic: Deakin University Press. p. 21-30.

; Rose, David. 2008. D. Genre relations: mapping culture. London: Equinox.

Meurer, José Luiz; Motta-Roth, Désirée. (org.). 2002. Gêneros textuais e práticas discursivas: subsídios para o ensino da linguagem. Bauru: EDUSC.

MiLLER, Carolyn R. 1984. Genre as social action. Quarterly Journal of Speech. 70(2): 151-176.

Mizukami, Maria da Graça Nicoletti. 1986. Ensino: as abordagens do processo. São Paulo: EPU.

Ramos, Rosinda Castro Guerra. 2012. Biodata: Desenvolvimento da Escrita Acadêmica em um Curso Semipresencial de Língua Inglesa. In: DiAs, R.; Dellísola, R. L. P. (Org.). Gêneros Textuais; Teoria e Prática de Ensino em LE. Campinas, SP: Mercado de Letras. p. 63-97.

. 2009a. ESP in Brazil: history, new trends and challenges. In: KRZANOWSKI, Mark. (ed.). English for Academic and Specific Purposes in Developing, Emerging and Least Developed Countries. Reading: Garnet Publishing Ltd. p. 63-80.

2009b. O livro didático de língua inglesa para o Ensino Fundamental e Médio: papéis, avaliação e potencialidades In: DiAs, Reinildes; CRISTÓVÃo, Vera Lúcia L. (org.). O livro didático de língua estrangeira: múltiplas perspectivas. Campinas, SP: Mercado de Letras. p. 173-198.

2005. Instrumental no Brasil: a desconstrução de mitos e a construção do futuro. In: FreIRE, Maximina. M. et al. (org.) Lingüística aplicada e contemporaneidade. São Paulo: Pontes. p. 108-134.

2004. Gêneros textuais: uma proposta de aplicação em cursos de inglês para fins específicos. The ESPecialist. 25(2): 107-129.

. 2000. Desenho de materiais baseado em gêneros: elaborando atividades para cursos de inglês instrumental. Workshop apresentado no XIV Seminário de Inglês Instrumental. UFJF, Juiz de Fora, Minas Gerais.

Ramos, Rosinda Castro Guerra; Lima-Lopes, Rodrigo; Gazotti-Vallim, Maria Aparecida. 2004. Análise de Necessidades: Identificando gêneros acadêmicos em um curso de leitura instrumental. The ESPecialist. 25(1):1-30. 
REGO, Tereza Cristina. 2002. Vygotsky: uma perspectiva histórico-cultural da educação. 14. Ed. Petropólis, RJ: Vozes.

Rojo, Roxane H.R. 2005. Gêneros do discurso e gêneros textuais: questões teóricas e aplicadas. In: Meurer, José Luiz; Bonini, Adair; MotTARотн, Désirée. (org.) Gêneros:teorias, métodos, debates. São Paulo: Parábola Editorial. p. 184-207.

StREVENS, P. 1988. ESP after twenty years: A re-appraisal. In: M. Tickoo (Ed.), ESP: State of the art . SEAMEO Regional Language Centre. p. 1-13.

Swales, John M. 2004. Research genres: explorations and applications. New York: Cambridge University Press. 1990. Genre analysis: English in academic and research settings. Cambridge: Cambridge University Press. . 1986. A genre-based approach to language across the curriculum. In: Tiскоо, Mackan L. (Ed.). Language across the curriculum. Singapore: Regional English Language Center. p. 10-22. 1981. Aspects of article introductions. (Aston ESP Research Report 1). Birmingham: University of Aston in Birmingham.

; FeAK, C. B. 2009. Abstracts and the Writing of Abstracts. Michigan: The University of Michigan Press.

Tomlimson, Brian. 2003a. Introduction: Are Materials Developing? In: (ed.). Developing Materials for language Teaching. Londres: Continuun. p. 1-11. 2003b. Materials Evaluation. In: (ed.). Developing Materials for language Teaching. Londres: Continuun. p. 15-36.

Ventura, Carolina S. M.; Farias, Angélica. 2002. Trabalhando com o Gênero Artigo Teórico em Sala de Aula de Leitura em Inglês. Comunicação apresentada no XVI Seminário Nacional de Inglês Instrumental e IV Seminário Nacional de Línguas Instrumentais. Centro Federal de Educação Tecnológica de Goiás, 19 a 23 de agosto.

Vigotski, Lev. S. 1988. Pensamento e Linguagem. 2 ed. São Paulo: Martins Fontes. Fontes. 1998. A formação Social da Mente. 6 ed. São Paulo: Martins

Williams, Marion; Burden, Robert. 1997. Psychology of Language Teachers. Cambridge: Cambridge University Press. 